\title{
Stress Analysis of The Effects of Mortar Thickness in Masonry Structures Using an Anisotropic Model
}

\author{
Bahattin Kimençe ${ }^{1}$ \\ ${ }^{1}$ Civil Engineering Faculty / Istanbul Technical University \\ Istanbul, Turkey \\ kimence@itu.edu.tr
}

\begin{abstract}
The aim of this study is to investigate the effect of mortar/brick thickness ratio, brick configuration on the masonry stresses and on masonry structure modelling. Different mortar/brick thickness ratios are micro-modelled by using stress- strain relationship. The results of these models are used to obtain the material properties of anisotropic macro-models in vertical and horizontal directions. The sample unreinforced masonry structures are simulated by the SAP2000 software using anisotropic material properties. In general masonry structures are composite materials that consists of brick and mortar. The main goal in modelling is to simulate a model that behaves close to the real structure as much as possible. Micro-modelling of masonry structure by considering its components individually is more realistic but not practical for large scale structures. In order to overcome this problem, macro-modelling is used in literature. Macro-model is obtained by smearing out the material properties of the micro-model to an anisotropic continuum material. Currently, most engineers simply analysis masonry structures with isotropic modelling in practice. However, presence of head and bed mortar joints in the construction of masonry causes the masonry to be anisotropic. Anisotropic modelling of a large scale structure does not need unreasonable effort as in micro-modelling and can be used instead of isotropic modelling easily in practice. Considering the horizontal and vertical loads in the plane, some wall types with rectangular cross-section, rectangular and arches cross-sections cavities were modeled as anisotropic and the effect of anisotropic material was investigated. In terms of displacements, an isotropic model and anisotropic models were found to be close to each other. However, when examined in terms of stresses, the maximum and minimum stresses in the masonary structure were changed.
\end{abstract}

Keywords: Unreinforced masonry, mortar/unit thickness ratio, micro model, macro model, homogenization, composite materials, stress analysis.

\section{Introduction}

The main purpose in modeling is to create a model that behaves as close as possible to the actual structure. Masonry is a composite material composed of brick and mortar. Micro-modeling, taking into account the individual components, is not practical for a more realistic but wide structure. To overcome this problem, the macro-model can be used to obtain an anisotropic continuity in the material properties of its components.

Therefore, the wall elements shown in Figure 1 cause the wall to be anisotropic, since they have different material properties [1]. In this study, the modulus of elasticity in the wall structure was obtained by taking into consideration the change in the thickness of the mortar [2]. Material constants in both directions were obtained by using the stress strain relations of the typical composite wall element in the plane stress effect.

An example of this type of masonry structure is shown in Figure 2 by the author of this study during the restoration of a minaret in Istanbul where the mortar / brick thickness ratio is close to 1. Therefore, the effect of mortar thickness and anisotropic modeling on the brick wall was investigated.

Only the horizontal component increased of the mortar thickness is shown figure 3. The micro-model is given in figure 3. The length of this modeled composite element was taken as $\mathrm{L}$, width $\mathrm{W}$, brick thickness $\mathrm{h}_{\mathrm{u}}$, mortar thickness $\mathrm{h}_{\mathrm{m}}$. Since the plane element is taken into consideration, the material constants are changed only in the direction 2 and in the direction 1, 3 has the same characteristics as shown fig. 3. 


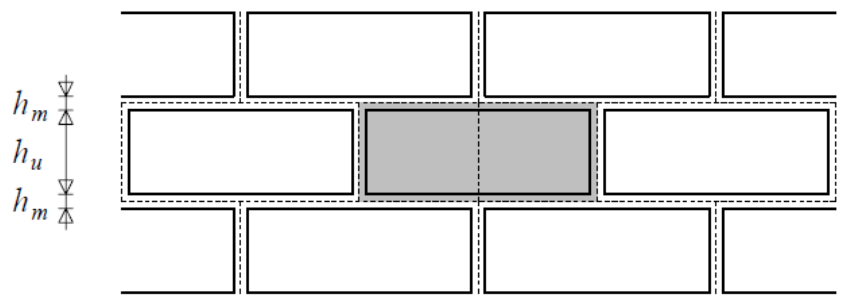

Fig. 1: Typical masonry wall model.

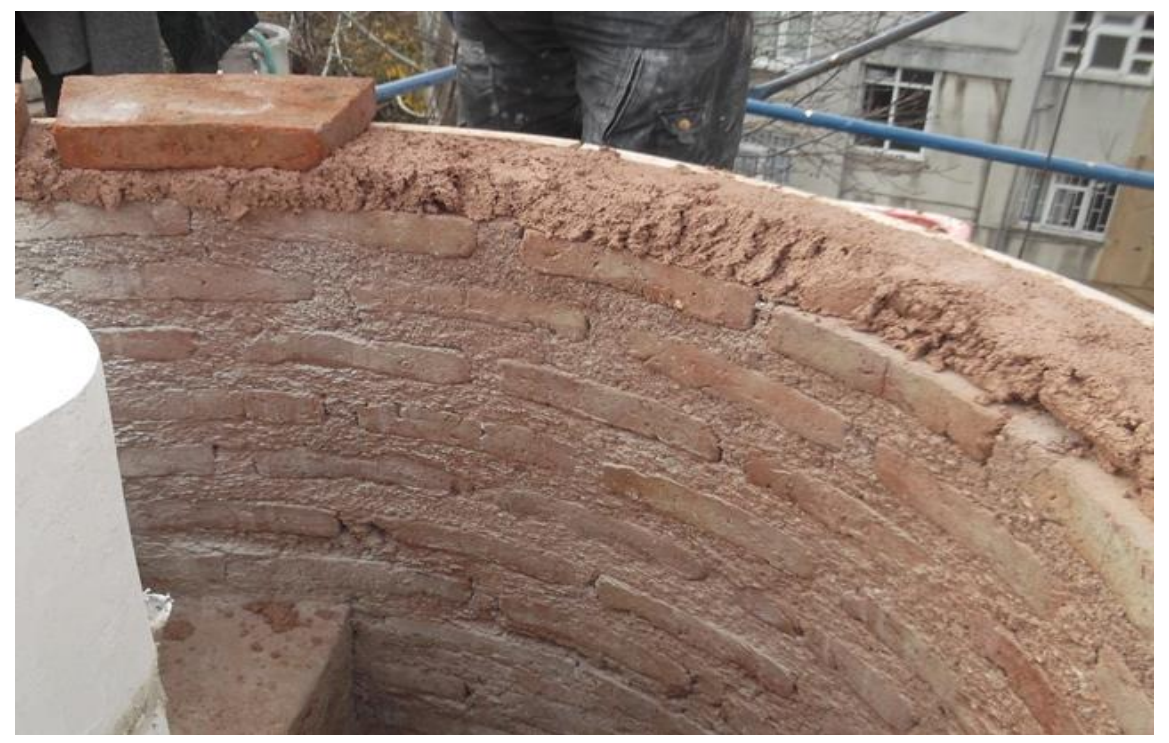

Fig. 2: Example of masonry minaret wall.

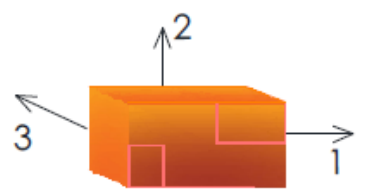

(a)

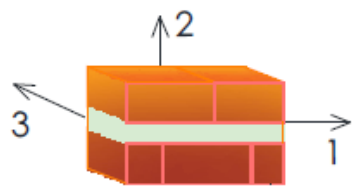

(b)

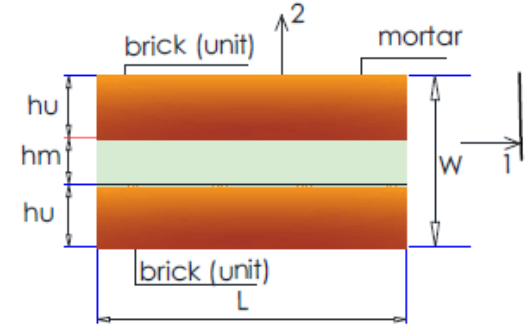

(c)

Fig. 3: (a) horizontal and vertical mortar thickness fixed, (b) horizontal mortar thickness increased, (c) micro-wall model.

\section{Micro Model in Composite Material}

In the stress-strain relations in linear elatic theory; there are generally 36 independent material constants. These material constants are reduced to 21 in anisotropic material, 13 in monoclin material (3 in symmetrical), 9 in orthotropic material, 5 in transverse isotropic material and 2 in isotropic material. In the case of plane stress, the transverse isotropic material has 4 constant independent stress-strain relations $\left(\mathrm{E}_{1}, \mathrm{E}_{2}, \mathrm{v}_{12}, \mathrm{G}_{12}\right)$. In this study, 4 independent material constants are obtained from stress-strain relations. Relations between stress-strain in anisotropic medium for plane stress state using Generalized Hooke Laws can be written as:

$$
\varepsilon_{1}=\frac{1}{E_{1}} \sigma_{1}-\frac{v_{12}}{E_{1}} \sigma_{2}, \quad \varepsilon_{2}=\frac{1}{E_{2}} \sigma_{2}-\frac{v_{12}}{E_{1}} \sigma_{1}, \quad \gamma_{12}=\frac{\tau_{12}}{G_{12}}
$$


Here, $E_{1}, E_{2}, v_{12}, G_{12}$ are the engineering constants of the material.

The micromechanical theories developed for conventional composites can be used to predict such properties. The assumptions regarding the both mortar and brick are linearly elastic isotropic materials [3-5].

\subsection{Calculation of Longitudinal Elastic Modulus $\left(E_{1}\right)$}

In the loading in direction 1 , the deflections (elongation ratios) are obtained from the conditions of equality (geometric conformity condition) Fig 4 a. The total force of equilibrium equations $F_{1}$, the force of the $F_{u}$ brick, the force of the mortar $\mathrm{F}_{\mathrm{m}}$, the total cross-sectional area of $\mathrm{A}_{1}$, the cross-sectional area of the brick, the cross-sectional area of the mortar, the ratio of the $\mathrm{V}_{\mathrm{u}}$ brick area to the total area, the ratio of the $\mathrm{V}_{\mathrm{m}}$ mortar area to the total area, the stress on the axis of $\sigma_{1}$, direction 1 . The stress in the $\sigma_{\mathrm{u}}$ brick is the stress in the $\sigma_{\mathrm{m}}$ mortar.

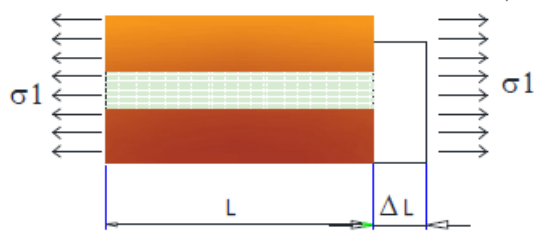

(a)

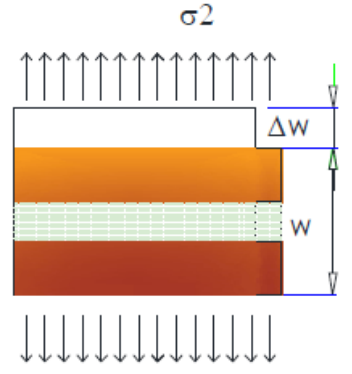

(b)

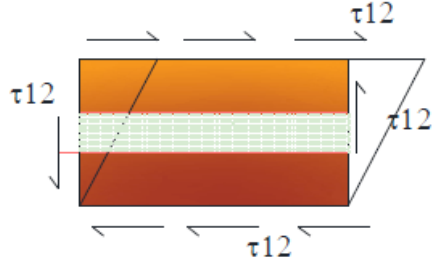

(c)

Fig. 4: Strain effect element in (a) direction 1, (b) direction 2 and (c) shear effect.

Equilibrium equation in direction 1 written as:

$$
\sigma_{1} A_{1}=\sigma_{m} A_{m}+\sigma_{u} A_{u}, \quad E_{1} \varepsilon_{1} A_{1}=E_{m} \varepsilon_{m} A_{m}+E_{u} \varepsilon_{u} A_{u}
$$

where $F_{1}=F_{m+} F_{u}, \sigma_{i=} E_{i} \varepsilon_{i}$ and $F_{i}=\sigma_{i} A_{i}$.

Material constant in direction 1 when considering equality of elongation rates can be calculated as:

$$
E_{1}=E_{m} V_{m}+E_{u} V_{u}
$$

The ratio of brick and mortar to total area is the $V_{m}=A_{m} / A_{1}, V_{u}=A_{u} / A_{1},\left(\mathrm{~V}_{\mathrm{m}}+\mathrm{V}_{\mathrm{u}}=1\right)$.

\subsection{Calculation of Transverse Elastic Modulus $\left(E_{2}\right)$}

Calculation of the material constant $\mathrm{E}_{2}$ is made by loading it in 2 directions, the condition of the stresses in the materials (from the condition of continuity) and the sum of the displacements $\left(\Delta_{2}=\Delta_{m}+\Delta_{m}\right)$ in the 2 direction as shown in Fig. $4 \mathrm{~b}$.

$$
\varepsilon_{2} W=\varepsilon_{m} W V_{m}+\varepsilon_{u} W V_{u}
$$


In the form of $E_{2}$ material constant in the direction 2 obtained as:

$$
\frac{1}{E_{2}}=\frac{V_{m}}{E_{m}}+\frac{V_{u}}{E_{u}}
$$

\subsection{Calculation of Poisson's Ratio $\left(\mathrm{u}_{12}\right)$}

In the case of the ratio of the deformations in the loading in direction $1 v_{12}=-\frac{s_{2}}{s_{1}}$ and the sum of vertical displacements Fig. $4 \quad \Delta_{W}=\Delta_{m w}+\Delta_{\text {uw }}$ as shown in Fig. 4

$$
\varepsilon_{1} v_{12} W=\varepsilon_{m} W V_{m} v_{m}+\varepsilon_{u} W V_{u} v_{u}
$$

Poisson's ratio obtained as:

$$
v_{12}=v_{m} V_{m}+v_{u} V_{u}
$$

\subsection{Calculation Shear Modulus $\left(\mathrm{G}_{12}\right)$}

Due to the sum of deformations due to shear stress $\Delta_{L}=\Delta_{m}+\Delta_{u}$ as shown Fig. 4, shear modulus $\mathrm{G}_{12}$ obtained as:

$$
\begin{gathered}
\gamma W=W V_{m} \gamma_{m}+W V_{u} \gamma_{u} \\
\frac{1}{G_{12}}=\frac{V_{m}}{G_{m}}+\frac{V_{u}}{G_{u}}
\end{gathered}
$$

The transition from the micro-model to the macro-model can be calculated using these constants in the actual structure after obtaining the corresponding elastic modulus values of the anisotropic continuity representations called macro models.

In this study, the mortar modulus of elasticity is $2000 \mathrm{Mpa}$, the brick modulus of elasticity is $20,000 \mathrm{Mpa}$, the mortar poisson ratio is 0.25 and the brick Poisson's ratio is 0.15 . $\mathrm{E}_{1}, \mathrm{E}_{2}, \mathrm{v}_{12}, \mathrm{G}_{12}$ are calculated used to Eqn. (3), (5), (7), (9) and results given Table 1. $E_{1}$ and $E_{2}$ diagram according to mortar thickness as shown Fig .5.

Table 1: Material coefficients according to the total thickness of the mortar thickness.

\begin{tabular}{|l|r|r|r|r|r|r|}
\hline & 1 & 2 & 3 & \multicolumn{1}{|c|}{4} & \multicolumn{1}{c|}{5} & 6 \\
\hline $\mathrm{V}_{\mathrm{u}}$ & 1 & 0,8 & 0,6 & 0,4 & 0,2 & 0 \\
\hline $\mathrm{V}_{\mathrm{m}}$ & 0 & 0,2 & 0,4 & 0,6 & 0,8 & 1 \\
\hline $\mathrm{E}_{1}(\mathrm{MPa})$ & 20000 & 16400 & 12800 & 9200 & 5600 & 2000 \\
\hline $\mathrm{E}_{2}(\mathrm{MPa})$ & 20000 & 7143 & 4348 & 3125 & 2439 & 2000 \\
\hline $\mathrm{V}_{12}$ & 0,15 & 0,17 & 0,19 & 0,21 & 0,23 & 0,25 \\
\hline $\mathrm{G}_{12}(\mathrm{MPa})$ & 8696 & 2924 & 1757 & 1256 & 978 & 800 \\
\hline
\end{tabular}




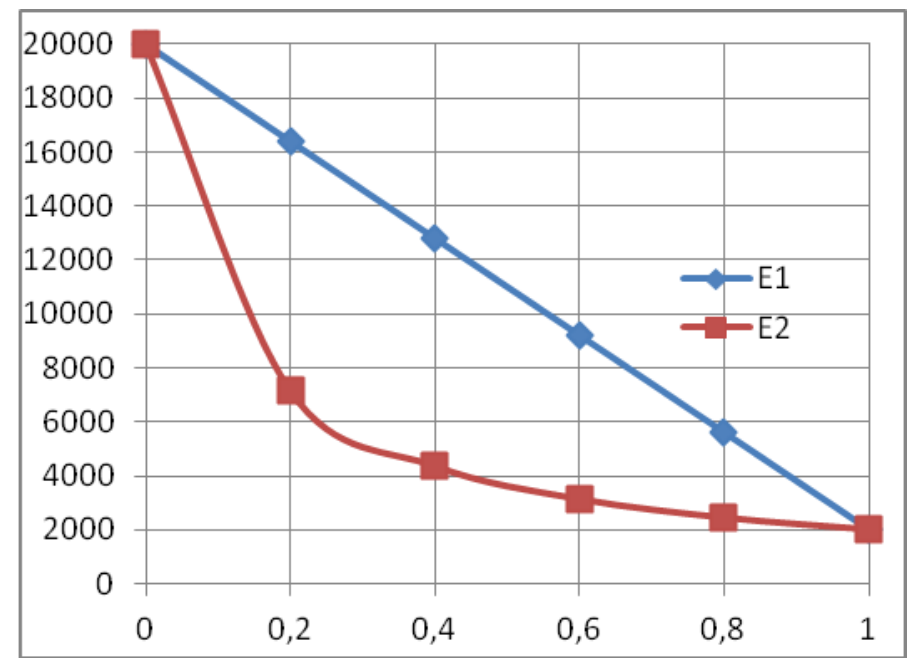

Fig 5: Elastic modules $\mathrm{E}_{1}, \mathrm{E}_{2}$, values containing material data of macro models are given in Table 1.

\section{Typical Walls}

Typical walls were taken into consideration and a typical wall of $4.0 \mathrm{~m}$ wide and $3.0 \mathrm{~m}$ high $.025 \mathrm{~m}$ thick was considered. Isotropic and anisotropic solutions were made with Sap2000 program [6]. 1.0MPa normal stress, 1.0MPa shear stress was applied on the upper surface of the wall as loading and isotropic anisotropic solutions were compared in some parts of the wall.

Isotropic walls were constructed by considering the $\mathrm{E}_{2}$ value and were used to compare the anisotropic wall models (Fig. 6). Wall cavity / total area: (a) wall cavity ratio $=0$, (b) wall cavity ratio $=0.185$, (c) wall cavity ratio $=0.615$. This is the rule of mixtures for composite materials based on the idea of idealizing two linear bows of brick and mortar in series. $\left(\mathrm{E}_{2}=\mathrm{E}_{1}\right)$.

Wall total area / gap area ratio $\sigma_{\max }, \sigma_{\min }$ brick thickness / mortar thickness ratio was calculated according to $\mathrm{V}_{\mathrm{m}} / \mathrm{V}_{\mathrm{u}}=0.2 / 0.8$ and $\mathrm{V}_{\mathrm{m}} / \mathrm{V}_{\mathrm{u}}=0.6 / 0.4 \sigma_{\max }, \sigma_{\min }$ was obtained as follows. According to the ratio of $\mathrm{V}_{\mathrm{m}} / \mathrm{V}_{\mathrm{u}}=0.6 / 0.4$ in the anisotropic environment, the $\sigma_{\max }$ diagram in the effect of horizontal load is given in figure 7 . In addition, $\sigma_{\max }$ values obtained from isotropic and anisotropic solutions are given in table 2.

In anisotropic environment, $\sigma_{\min }$ diagram is shown in figure 8 according to the ratio of $\mathrm{V}_{\mathrm{m}} / \mathrm{V}_{\mathrm{u}}=0.6 / 0.4$. In addition, $\sigma_{\max }$ values obtained from isotropic and anisotropic solutions are given in table 3 .

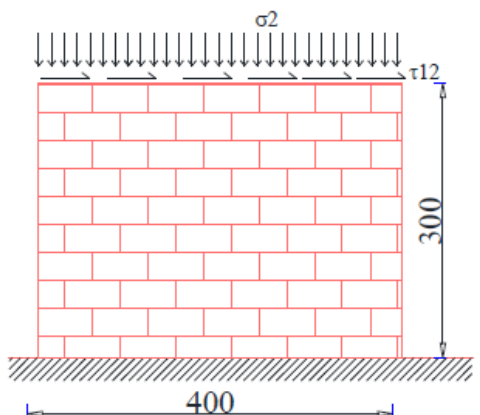

(a)

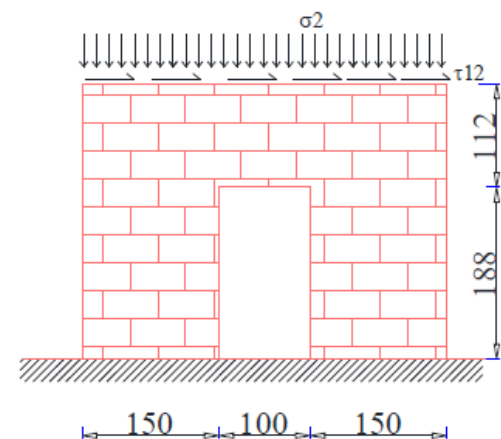

(b)

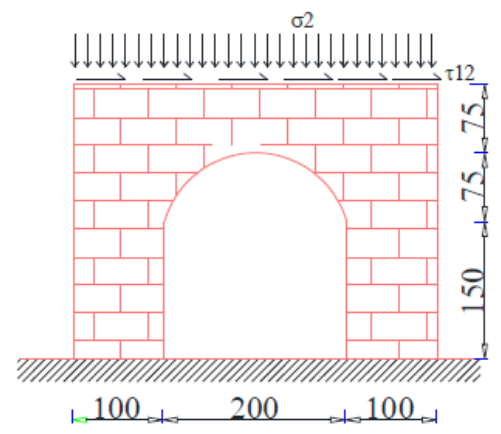

(c)

Fig. 6 Wall models (a) filled wall, (b) rectangular cavity, (c) circular/rectangular cavity. 


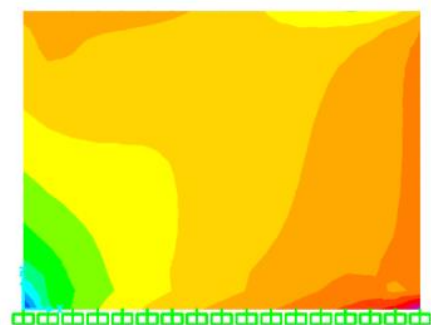

(a)

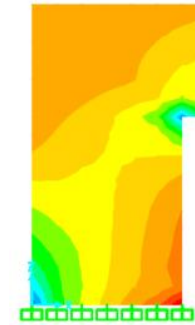

(b)

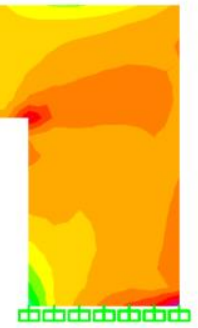

(c)

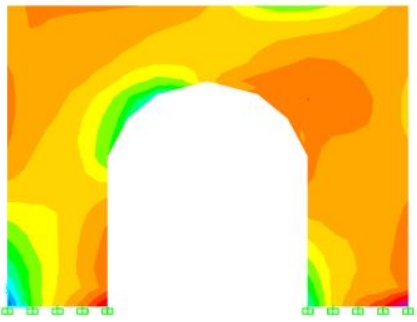

Fig. 7: $\sigma_{\max }$ diagrams in horizontal load effect $\mathrm{V}_{\mathrm{m}} / \mathrm{V}_{\mathrm{u}}=0.6 / 0.4$.

Table 2: Material coefficients according to the total thickness of the mortar thickness.

\begin{tabular}{|c|c|c|c|c|c|c|c|}
\hline & horizontal load & a2 & b2 & c2 & a4 & b4 & c4 \\
\hline \multirow{3}{*}{$\begin{array}{c}\sigma_{\max } \\
\text { Mpa } \\
\text { ratio }\end{array}$} & anisotrop & 7.153 & 11.586 & 18.241 & 7.792 & 12.99 & 19.31 \\
\hline & isotrop & 6.642 & 11.001 & 18.054 & 6.691 & 11.06 & 18.12 \\
\hline & anisotrop/isotrop & 1.077 & 1.053 & 1.010 & 1.165 & 1.175 & 1.066 \\
\hline \multirow{3}{*}{$\begin{array}{l}\mathrm{U} 1 \\
\mathrm{~mm} \\
\text { ratio }\end{array}$} & anisotrop & 2.230 & 3.645 & 6.413 & 5.078 & 8.164 & 14.23 \\
\hline & isotrop & 2.259 & 3.934 & 7.198 & 5.182 & 9.012 & 16.48 \\
\hline & anisotrop/isotrop & 0.99 & 0.93 & 0.89 & 0.98 & 0.91 & 0.86 \\
\hline \multirow{3}{*}{$\begin{array}{l}\mathrm{U} 2 \\
\mathrm{~mm} \\
\text { ratio }\end{array}$} & anisotrop & 1.131 & 1.269 & 1.386 & 2.549 & 2.821 & 3.039 \\
\hline & isotrop & 1.170 & 1.397 & 1.618 & 2.675 & 3.191 & 3.695 \\
\hline & anisotrop/isotrop & 0.97 & 0.91 & 0.86 & 0.95 & 0.88 & 0.82 \\
\hline
\end{tabular}

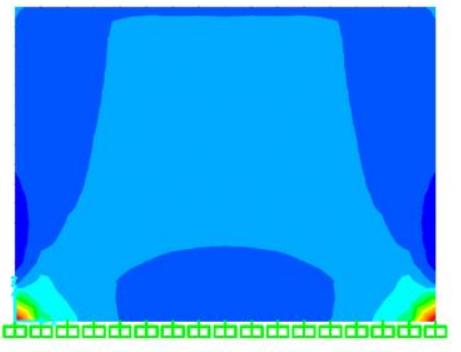

(a)

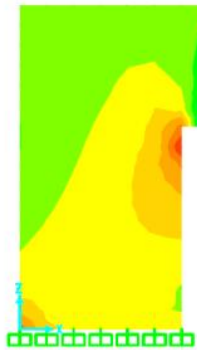

(b)

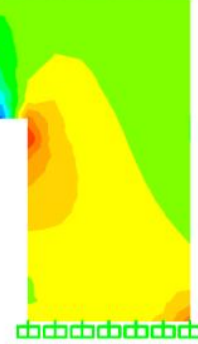

(c)

Fig. 8: $\sigma_{\min }$ diagrams in vertical load effect $\mathrm{V}_{\mathrm{m}} / \mathrm{V}_{\mathrm{u}}=0.6 / 0.4$.

Table 3: Material coefficients according to the total thickness of the mortar thickness

\begin{tabular}{|c|c|c|c|c|c|c|c|}
\hline & vertical load & a2 & b2 & c2 & a4 & b4 & c4 \\
\hline \multirow{3}{*}{$\begin{array}{c}\sigma_{\min } \\
\text { Mpa } \\
\text { ratio }\end{array}$} & anisotrop & 1.425 & 2.852 & 4.64 & 1.634 & 2.89 & 4.622 \\
\hline & isotrop & 1.284 & 2.965 & 4.933 & 1.303 & 2.971 & 4.941 \\
\hline & anisotrop/isotrop & 1.110 & 0.962 & 0.941 & 1.254 & 0.973 & 0.935 \\
\hline \multirow{3}{*}{$\begin{array}{l}\mathrm{U} 2 \\
\mathrm{~mm} \\
\text { ratio }\end{array}$} & anisotrop & 0.414 & 0.616 & 1.182 & 0.941 & 1.385 & 2.614 \\
\hline & isotrop & 0.415 & 0.637 & 1.287 & 0.948 & 1.455 & 2.94 \\
\hline & anisotrop/isotrop & 1.00 & 0.97 & 0.92 & 0.99 & 0.95 & 0.89 \\
\hline
\end{tabular}




\section{Conclusion}

In this study, micro-modelled walls are homogenized to anisotropic continuum wall models and their material properties are presented in Table 3 and Fig. 6. It is observed that the Elastic modulus of anisotropic wall models in vertical direction $\mathrm{E}_{2}$ is always higher than the one in horizontal direction $\mathrm{E}_{1}$ for the three wall configurations considered herein.

In vertical direction, the Elastic modulus values $\mathrm{E}_{2}$ of anisotropic walls $\mathrm{A}$ and $\mathrm{B} 1$ are around $\mathrm{E}_{1}$ is 2.94 times larger than their isotropic counterparts $\mathrm{E}_{2}$. Therefore, we can conclude that rigidity of anisotropic model in vertical direction is always higher than that that of its isotropic counterpart but this deviation increases with increasing mortar thickness equals brick thickness.

Recalling the fact that most of masonry structure failures take place due to lateral loading, therefore the rigidity in horizontal direction is important to be investigated. Comparing data for anisotropic wall models a, b, c given in Table 2 and in Table 3, it is observed that the effect of mortar thickness increased.

The wall structures are simulated using anisotropic and isotropic wall data of (a), (b), (c), and the displacements at the top level are presented in Table 2 and Table 3. Comparison of a, b, and c structure model displacements given in Table 2 shows that model $\mathrm{c}$ displaced around vertical displacement $\mathrm{u} 2$ is 0.82 times larger than their isotropic counterparts.

The anisotropic / isotropic ratio decreases as the cavity ratio increases. The effect of anisotrp solution increases as the rate of mortar increases.

\section{References}

[1] P.B. Lourenco, "Current experimental and numerical issues in masonry research", in Proceedings of the International Workshop on Masonry Walls and Earthquakes, Universidade do Minho, Guimaraes, Portugal, 2004, pp. 119-136.

[2] B. Kimence, S. Demirkan, H. Ergun "Analysis of the effects of mortar thickness and wall building technique in masonry structures using an anisotropic model," Applied Mechanics and Materials, vol. 847, pp. 146-155, 2016.

[3] G. Castori, Strengthening of Masonry Elements. Lambert Academic Publishing, 2012.

[4] K. K. Chavla, Composite Materials, Science and Engineering. Springer, 2012.

[5] H. Altenbach, J. Altenbach, W. Kissing, Mechanics of Composite Structural Element. Springer, 2004.

[6] SAP2000 V.15.2.1. Computer and Structures Software. 